\title{
Scenario Analysis of Enterprise Annuity Supervision in China
}

\author{
Zhang Xuezhou \\ Department of Management and Economics \\ Beijing Institute of Technology \\ Beijing, China \\ e-mail:qkangle@163.com \\ Qiao Kai \\ Department of Management and Economics \\ Beijing Institute of Technology \\ Beijing, China \\ e-mail:qkangle@163.com
}

\author{
Dong Peiwu \\ Department of Management and Economics \\ Beijing Institute of Technology \\ Beijing, China \\ e-mail:qkangle@163.com
}

\begin{abstract}
This paper studied the supervision of the enterprise annuity in China by the method of scenario analysis. Since supervision is closely related to the benefit distribution among the main participants of enterprise annuity, we present a game model to optimize the benefit distribution firstly. By calculating the model, we get the equilibrium solution of the game and find out the best probability of rent-seeking behavior. Then, we introduce a new method, scenario analysis to do the further research. Combining the game model and the method, we choose two factors, the penalty coefficient $f 1$ and $f 2$, as example to simulate scene. According to the scene simulated, we find that, as shown in Figure 1 and Figure 2, increasing the penalty coefficient $f 1$ and $f 2$ can ease the rent-seeking behavior. However, as the penalty coefficient f1 and f2 become larger, increasing them is no longer an effective way to prevent rent-seeking behavior.
\end{abstract}

Keywords-enterprise annuity fund; supervision ;scenario analysis; game theory; benefit distribution

\section{INTRODUCTION}

The enterprise annuity fund, which starts from the midnineteenth century, is originated from the enterprise pension system and the retirement benefit system in the early western society. It has longer history than the public old-age insurance plan. In the mid-nineteenth century, corporations like the Gutehoflhungs-hütte and the Siemens \&Halske begin to set up some enterprise aid institutions. Those institutions are responsible for offering help to the old or the disabled workers in the corporation.

Since the development of the enterprise annuity fund in western countries has been over two hundred years, the financial supervision, investment strategy, risk management and the product are more perfect. Moreover, the participants have more clear division of labor. In scholarship, the researches on the enterprise annuity fund are mainly around a particular player. The study on the cost and the income of a particular player includes: Lachance and Mitchell2(2002) presented a bonded defined contribution(DC) scheme, and found out that this would lead moral hazard. Namely, the workers would prefer to invest more on the high risk asset to acquire a higher earning. To solve this problem, Feldstein and Ranguelova3(2002), Pennacchi4(1998) et al proposed to use market index to measuring DC scheme asset. Ken Johnton(2001)et al used Monte Carlo model to compare the investment risk between the defined contribution pension and the defined benefit pension. He thought the risk of the DC schemes could be well controlled by taking some efficient measures. Haberman and Vigna5(2003) used Bellman equation to make research on the defined contribution pension. By changing the utility function and the coefficient of the assets, they showed that the different best investment strategy of the DC scheme.

China begins to set up basic pension insurance in 1980s. Then, in 1990s, China starts to set up enterprise annuity fund and makes it a supplement to the basic pension insurance. Because enterprise annuity fund starts relatively late in China, it is lack of study. In China, the researches on enterprise annuity fund are mainly around system study. For example, Shaomin Cui et al(2002) did some analysis on the principle, operation and management of the complement endowment insurance. She also used a lot of models to support her analysis and makes a prediction for the development trends of Chinese enterprise endowment insurance. YaqinGao(2004), Tiancheng Li10(2005) used general principal agent model to study the operation of the enterprise annuity fund. They thought that constructing a highly efficient governance structure, incentive compatible mechanism, compensation mechanism, multi-level supervision system for the enterprise annuity fund is necessary. Qiaoqiao Peng and GuoHui Wang(2008) analyzed the risk during the corporation pension fund investment. They made the study from both macro and micro perspective and offered some advises to the investor. After considering the profitability, the risk and the 
liquidity of the corporation pension fund, Qingtian $\mathrm{Wu}(2010)$ presented the two main mission of the investment manager during the operation of the fund are maintaining the value and increasing the value. Based on it, he constructed a principal-agent model and discussed the incentive problem of the investment manager.

From the statement above, we can conclude that the study on the enterprise annuity fund mainly concentrates on the system of enterprise annuity fund, investment strategy, risk management, tax preferences and the business finance. The study on all stakeholders during the whole operation process of the enterprise annuity fund is relatively less. Thus this paper will proceed from the actual situation of China and use game theory and the scenario analysis to study the problem. It has important theoretical significance and fills the gap of the enterprise annuity fund study. In the paper, a game model of the enterprise annuity fund is presented. Then, some scenario analyses are made based on it. At last, we will give some suggestions and measures as conclusion.

\section{GAME MODEL AMONG MAIN PLAYERS}

Trustee, who takes responsibility for the safety of the fund property, locates in the core position of the operation of corporate pension fund. Both the custodian and the investment manager are the agents of the trustee. The custodian is responsible for supervising the investment managers. However, the custodian may be dedicated to perform their duties or be possible to do a rent-seeking behavior with the investment manager. If he takes rentseeking activities, it will damage the legitimate rights and interests of the beneficiaries.

The duty of the account manager is to check the property changes of corporate pension fund account with the trustee. As he is not closely related to the investment manager, he will not be included in the discussion and this will not affect our conclusions. If it occurs rent-seeking behavior between the investment manager and the custodian, which is also to say that they form a coalition, the beneficiary and the trustee will be the biggest victim. Thus to reduce the loss of their own and the loss of the beneficiary, the trustee must take some measures to lessen the incidence of the rent-seeking behavior between the investment manager and the custodian during the investment management process. Therefore, according to the discussion above, it forms a game among 3 playersthe trustee, the custodian and the investment manager.

In this tripartite game process, the custodian and the investment manager have two strategies: rent-seeking or non-rent-seeking. According to the choice of the custodian and the investment manager, the trustee also has two strategies: supervision or non-supervision. If he chooses supervision, then there is a certain probability that he will find out the rent-seeking behavior. Once he finds out the rent-seeking, the investment manager and the custodian will be punished appropriately. When establishing the payoff matrix for the main players, we generally assume that the players' payments are relative values, which is also to say that the payments varies from the investment manager and the custodian abiding by the contract to doing rent-seeking behavior.

When each player abides by the contract, all the payment value is 0 (assumed that the trustee does not supervise at the same time).The assumptions of the model are as follows:

(1) The 3 players of the game are the trustee, the custodian and the investment manager. There is a noncooperative game between the trustee and the other two players.

(2) We assume that the probability of the investment management manager taking rent-seeking activities is $\eta$.We also assume that the trustee will supervise the rentseeking between the custodian and the investment manager with a certain probability $\delta$ and the successful probability of the supervision is $\gamma$.

(3) We assume that if the investment manager takes rent-seeking activities with the custodian, he will get excess profit $\mathrm{P}$. Then he will provide the rent $R(R<P)$ to the custodian. Thus the trustee or the beneficiaries will get the loss $m P$, where $m$ is the coefficient of loss expansion for the trustee. If the trustee chooses to supervise the rent-seeking behavior, he will have to pay $C$ as the monitoring costs.

(4) In the case that the custodian and the investment manager take rent-seeking activities and the trustee does not supervise, the payoff of the custodian, the investment manager and the trustee are: $R, P-R,-m P$.

(5) In the case that the custodian and the investment manager take rent-seeking activities and the trustee does not successfully supervise, the payoff of the custodian, the investment manager and the trustee are: $R, P-R,-m P-C$.

(6) In the case that the custodian and the investment manager take rent-seeking activities and the trustee successfully supervises, the trustee confiscates the rentseeking income of the custodian and the investment manager. Moreover, he will also give the punishment $f_{1} R$ and $f_{2}(P-R)$ to the custodian and the investment manager, where $f_{1}$ and $f_{2}$ are penalty coefficient and they has been simplified to a linear function. In severe cases, the trustee may replace the custodian and the investment management. The payoffs of the three players are $-f_{1} R$,

$$
-f_{2}(P-R), f_{1} R+f_{2}(P-R)-C \text { respectively. }
$$

(7) In the case that the custodian and the investment manager do not take rent-seeking activities and the trustee does not supervise, the payoff for each players are respectively $0,0,0$.

(8) In the case that the custodian and the investment manager do not take rent-seeking activities and the trustee supervises, the payoff for each players are respectively 0,0 , $-C$.

According to the model presented above and the Nash equilibrium theory, we get the payoff matrix of the tripartite game as follows.

(1) According to the condition of the tripartite game, in the case that the occurrence probability of rent-seeking activities is $\eta$, the expected return of the trustee taking supervision strategy or not are respectively:

$$
\begin{aligned}
& E_{1}=\eta\left\{\left[f_{1} R+f_{2}(P-R)-C\right] y+(-m P-C)(1-\gamma)\right\}+(1-\eta[-C \gamma-C(1-\gamma)]) \\
& E_{2}=\eta(-m P)+(1-\eta) \times 0=-\eta m P
\end{aligned}
$$


When $E_{1}=E_{2}$, the best probability of the custodian and investment manager taking rent-seeking activities is :

$$
\eta^{*}=\frac{C}{f_{1} R \gamma+f_{2}(P-R) \gamma+m P \gamma}
$$

(2) When the trustee supervises the custodian in a certain probability $\delta$, the expected return of the custodian taking rent-seeking activities or not are:

$E_{3}=\delta\left[-f_{1} R \gamma+R(1-\gamma)\right]+(1-\delta) R$

$E_{4}=0$

When $E_{3}=E_{4}$, the custodian gets the game equilibrium. The best probability of the trustee supervising is:

$$
\delta^{*}=\frac{1}{\gamma\left(1+f_{1}\right)}
$$

(3) When the trustee supervises the custodian in a certain probability, the expected return of the investment manager taking rent-seeking activities or not are:

$E_{5}=\delta\left[-f_{2}(P-R) \gamma+(P-R)(1-\gamma)\right]+(1-\delta)(P-R)$

$E_{6}=0$

When $E_{5}=E_{6}$, the investment manager gets the game equilibrium. The best probability of the trustee supervising is:

$$
\delta^{* *}=\frac{1}{\gamma\left(1+f_{2}\right)}
$$

Above all, Nash equilibrium solution of this tripartite game mixed strategy is:

$$
\begin{aligned}
& \left\{\eta^{*}, \delta^{*}\right\}=\left\{\frac{C}{f_{1} R \gamma+f_{2}(P-R) \gamma+m P \gamma}, \frac{1}{\gamma\left(1+f_{1}\right)}\right\} \\
& \left\{\eta^{*}, \delta^{* *}\right\}=\left\{\frac{C}{f_{1} R \gamma+f_{2}(P-R) \gamma+m P \gamma}, \frac{1}{\gamma\left(1+f_{2}\right)}\right\}
\end{aligned}
$$

\section{SCENARIO ANALYSIS}

To analysis an economic problem, some econometrics approaches may be helpful. However, as for the operation of the corporation pension fund, these approaches may be not that useful because these approaches need a lot of data to support and the data of the fund are usually hard to acquire. Thus we will abandon these ordinary approaches and use a new method, scenario analysis, to make research. We utilize scenario analysis to do sensitivity analysis, which can observe the change between each two variables directly. In the following part, we will take the influence factors, $f_{1}$ and $f_{2}$, as example and observe the changes. Based on the changes, some suggestions are given.

Assuming the initial value of all variables are as follows: $\gamma=0.5, m=1, f_{1}=2$ and $f_{2}=2.5$. Due to the $\mathrm{C}, \mathrm{P}$ and $\mathrm{R}$ are with value unit, their units used will not affect the results in calculation process. Thus, in order to facilitate and consistent with representation of the profit allocation, here we present them as a percentage of the value of enterprise annuity fund property. Meanwhile, assume $C=0.05 \%$ ( according to the policy, which acquires the trustee annual management fees is not higher than $0.2 \%$ of enterprise annuity fund managed ) , $P=0.5 \%, \quad R=0.25 \%$ 。

\section{A. Effect of $f_{1}$ change upon $\eta$ and $\delta$}

As shown above, in order to understand the effect of the change of $f_{1}$ upon $\eta$ and $\delta$ better, we need to compute partial differential of $f_{1}$ by (4) and (5), which can be proved as follows:

$$
\begin{aligned}
\frac{\partial \eta^{*}}{\partial f_{1}} & =-\frac{C R \gamma}{\left[f_{1} R \gamma+f_{2}(P-R) \gamma+m P \gamma\right]^{2}} \\
\frac{\partial \delta^{*}}{\partial f_{1}} & =-\frac{\gamma}{\left[\gamma\left(1+f_{1}\right)\right]^{2}}
\end{aligned}
$$

$\frac{\partial \delta^{* *}}{\partial f_{1}}=0$

Since $C R \gamma>0, \quad\left[f_{1} R \gamma+f_{2}(P-R) \gamma+m P \gamma\right]^{2}>0$ and $\left[\gamma\left(1+f_{1}\right)\right]^{2}>0$, it can be derived as:

$$
\frac{\partial \eta^{*}}{\partial f_{1}}<0, \frac{\partial \delta^{*}}{\partial f_{1}}<0, \frac{\partial \delta^{* *}}{\partial f_{1}}=0
$$

Furthermore, $\frac{\partial^{2} \eta^{*}}{\partial f_{1}^{2}}$ is the ratio of the probability change of investment manager taking rent-seeking activities to penalty coefficient change on the custodian. Compute second-order partial differential of $f_{1}$ by (4) and (5), which can be proved as follows:

$$
\begin{aligned}
& \frac{\partial^{2} \eta^{*}}{\partial f_{1}^{2}}=\frac{2 C R^{2} \gamma^{2}}{\left[f_{1} R \gamma+f_{2}(P-R) \gamma+m P \gamma\right]^{3}}>0 \\
& \frac{\partial^{2} \delta^{*}}{\partial f_{1}^{2}}=\frac{\gamma^{2}}{\left[\gamma\left(1+f_{1}\right)\right]^{3}}>0
\end{aligned}
$$

The results indicate that the relationship is negative between $f_{1}$ and $\eta^{*}$. It means larger penalty coefficient on the custodian, the smaller probability of investment manager taking rent-seeking activities. Its second derivative is positive, which shows the rate of change is decreasing. That $f_{1}$ penalty coefficient on the custodian is increasing in the same amount indicates that probability change decreases smaller. Probability of investment manager taking rent-seeking activities $\eta^{*}$ is decreasingly sensitive with the increasing penalty coefficient on the custodian. Thus, to lower the occurrence probability of rent-seeking behavior, we can simply increasing the penalty on the custodian. If the probability of rent-seeking behavior becomes smaller, the loss of the investor will also become smaller. However this strategy is not always useful. For example, assuming $f_{1}$ rises from 2 to 15 as per interval of $0.1, \eta^{*}$ decreases from 0.6153 to 0.2051 , 
$\delta^{*}$ decreases from 0.6666 to $0.125, \delta^{* *}$ no change. Change of $\eta$ and $\delta$ in relation to change of $f_{1}$ are shown respectively in Fig 1 :

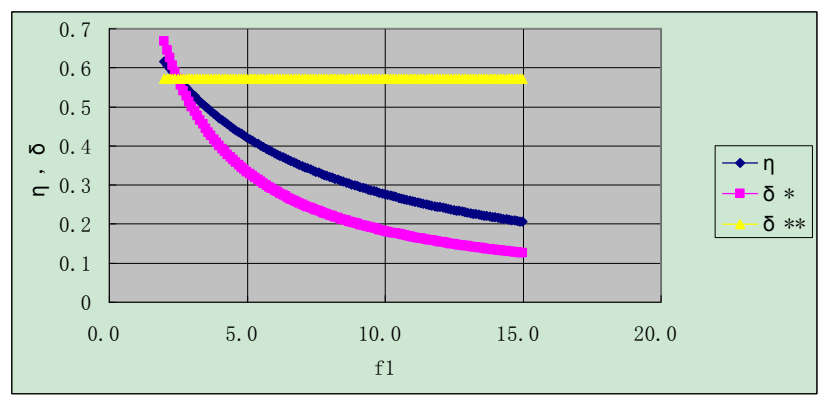

Figure 1. Tendency chart of $\eta$ and $\delta$ with $f_{1}$

From figure 1, it is clear to see that when the penalty coefficient $f_{1}$ is bigger than 10 , the change of the probability $\eta$ and $\delta$ are rather small. Thus, when the penalty coefficient $f_{1}$ is smaller than 7.5 , increasing $f_{1}$ is a good way to prevent rent-seeking behavior. However when the penalty coefficient $f_{1}$ is bigger than 10 , increasing $f_{1}$ is not that useful and effective.

\section{B. Effect of $f_{2}$ change upon $\eta$ and $\delta$}

In the same way, compute partial differential of $f_{2}$ by (4) and (5), which can be proved as follows:

$$
\begin{aligned}
& \frac{\partial \eta^{*}}{\partial f_{2}}=-\frac{C(P-R) \gamma}{\left[f_{1} R \gamma+f_{2}(P-R) \gamma+m P \gamma\right]^{2}} \\
& \frac{\partial \delta^{*}}{\partial f_{2}}=0 \\
& \frac{\partial \delta^{* *}}{\partial f_{2}}=-\frac{\gamma}{\left[\gamma\left(1+f_{2}\right)\right]^{2}}
\end{aligned}
$$

Since $C(R-R) \gamma>0 \quad\left[f_{1} R \gamma+f_{2}(P-R) \gamma+m P \gamma\right]^{2}>0$, and $\left[\gamma\left(1+f_{2}\right)\right]^{2}>0$, we can get: $\frac{\partial \eta^{*}}{\partial f_{2}}<0, \frac{\partial \delta^{*}}{\partial f_{2}}=0$, $\frac{\partial \delta^{* *}}{\partial f_{2}}<0$

Furthermore, $\frac{\partial^{2} \eta^{*}}{\partial f_{2}{ }^{2}}$ is the ratio of the probability change of investment manager taking rent-seeking activities to penalty coefficient change on the investment manager. Compute second-order partial differential of $f_{2}$ by (4) and (5), which can be proved as follows:

$$
\begin{aligned}
& \frac{\partial^{2} \eta^{*}}{\partial f_{2}^{2}}=\frac{2 C(P-R)^{2} \gamma^{2}}{\left[f_{1} R \gamma+f_{2}(P-R)+m P \gamma\right]^{3}}>0 \\
& \frac{\partial^{2} \delta^{* *}}{\partial f_{2}{ }^{2}}=\frac{\gamma^{2}}{\left[\gamma\left(1+f_{2}\right)\right]^{3}}>0
\end{aligned}
$$

The results indicate that the relationship is negative between $f_{2}$ and $\eta^{*}$. It means that the larger penalty coefficient we set, the smaller probability of investment manager taking rent-seeking activities will be. Its second derivative is positive, which shows the rate of the change is decreasing.

$f_{2}$, the penalty coefficient on the investment manager, is increasing in the same amount indicates that the probability change decreases smaller. Probability of investment manager taking rent-seeking activities $\eta^{*}$ is decreasingly sensitive with the increasing penalty. Assuming $f_{2}$ rises from 2.5 to 15.5 as per interval of 0.1 , $\eta^{*}$ decreases from 0.6154 to $0.2051, \delta^{*}$ changes $0, \delta^{* *}$ decreases from 0.5714 to 0.1212 .The change of $\eta^{*} \delta^{*}$ and $\delta^{* *}$ in relation to the change of $f_{2}$ are shown respectively in Fig 2:

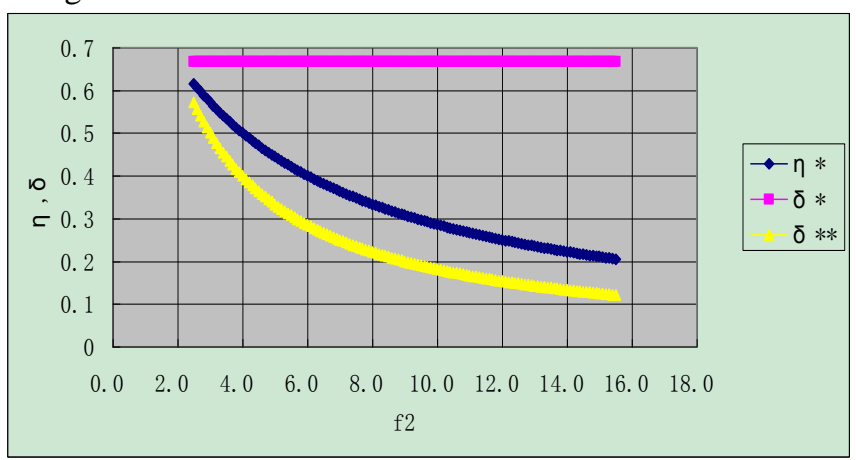

Figure 2. Tendency chart of $\eta$ and $\delta$ with $f_{2}$

From the figure above, we can clearly see that when $f_{2}$ increases larger, the probability is become smaller. However, as $f_{2}$ increases more, the change of the occurrence probability also becomes smaller. Which is to say that, when $f_{2}$ is large enough, we will take more effort to lower the probability of rent-seeking behavior. So increasing $f_{2}$ is not a wise way in this case.

\section{CONCLUSION}

In this paper, we present a game model of corporate pension fund to find out the relationship among the influence factor. Then we introduce a new method, scenario analysis. Combining the game model and the method, we make some analyses to study the relationship among $f_{1}, f_{2}, \eta$ and $\delta$. We find out that $f_{1}$ and $f_{2}$ both have negative effects on $\eta$ and $\delta$, which is to say that when we increase the penalty, the occurrence probability of rent-seeking behavior is decreasing. Thus increasing penalty is a good way to prevent rent-seeking behavior However this way is not always effective. When $f_{1}$ and $f_{2}$ are relatively large, increasing penalty is no longer a useful way.

Future work will concentrates on the analysis of other influence factors. In addition, extensive study of the corporate pension fund is still necessary. 


\section{REFERENCES}

[1] JL Campbell, Dan S.Dhaliwal, and William C.Schwartz Jr, "Financing Constraints and the Cost of Capital:Evidence from the Funding of Corporate Pension Plans," the Review of Financal Studies, vol 25, Nov 2011, pp. 868-912, doi: 10.1093/rfs/hhr119

[2] D Anantharaman, YG Lee, "Managerial Risk Taking Incentives and Corporate Pension Policy," Jornal of Financial Economics, vol 111, Feb 2014, pp. 328-351, doi: 10.1016/j.jfineco.2013.10.009

[3] E Amir, Y Guan, and D Oswald,'The Effect of Pension Accounting on Corporate Pension Asset Allocation," Review of accounting studies, vol 15, June 2010, pp 345366, doi: 10.1007/s11142-009-9102-y

[4] D McCarthy, D Miles, "Optimal portfolio allocation for corporate pension funds," European Financial Management, vol 19, June 2013, pp599-629, doi:10.1111/j.1468036X.2010.00594.x

[5] E.Philip Davis, Leo De Haan, "Pension Fund Finance and Sponsoring Companies," Journal of Pension Economics and Finance, vol 11, July 2012, pp 439-463, doi: $10.1017 / \mathrm{S} 1474747212000030$

[6] KP Ambachtsheer, Pension revolution: a solution to the pensions crisis, WILEY FINANCE,2011

[7] John Kiff, Michael Kisser, Mauricio Soto, The Impact of Longevity Improvements on U.S Corporate Defined Benefit Pension Plans, Andrews McMeel, 2012

[8] Ma Chi, "Pension Fund Investment Performance Evaluation Based on RAROC," China Bussiness and Market, vol 28, March 2014, pp:117-121(in Chinese)

[9] Xin Zhang, "Issues on Tax-Abatement under Budgeted Revenue-enhancing Constraints," Taxation Research, vol 294, Nov. 2009, pp. 35-38(in Chinese)

[10] Wang Gangyi, Lv Yongjie, "Modeling and forecasting of enterprise pension DC plan with ADL interest rates," Journal of System Engineering, vol 28, Nov 2013, pp. 427436(in Chinese)

[11] Yi Zhang, "The Model of Loss Probability on Investment Risk of Enerprise Annuity," Journal of Taishan University vol .35, Nov. 2013, pp. 33-37(in Chinese) 